\title{
WEIGHT TRENDS AMOUNG WOMEN ENGAGING IN EXERCISE AND NUTRITIONAL COUNSELLING AS SUPPORTIVE CARE DURING ADJUVANT BREAST CANCER TREATMENT
}

Cheri Van Patten ${ }^{1}$, Amy Kirkham², Kelcey Bland ${ }^{3}$, Alis Bonsignore ${ }^{4}$, Don McKenzie ${ }^{5}$, Karen Gelmon ${ }^{6}$, Kristin Campbell ${ }^{7}$

${ }^{1} \mathrm{BC}$ Cancer, Nutrition and Rehabilitation, Vancouver, Canada; ${ }^{2}$ University of Alberta, Department of Biomedical Engineering, Edmonton, Canada, ${ }^{3}$ Australian Catholic University, Melbourne, Australia, ${ }^{4}$ University of Toronto, Toronto, Canada, ${ }^{5}$ University of British Columbia, School of Kinesiology, Vancouver, Canada, ${ }^{6}$ BC Cancer, Medical Oncology, Vancouver, Canada, ${ }^{7}$ University of British Columbia, Physical Therapy, Vancouver, Canada

\section{Introduction:}

Weight gain commonly occurs in women undergoing treatment for breast cancer. In addition to body image issues and psychological distress, weight gain is associated with an increased risk of comorbidities including cardiovascular disease as well as cancer recurrence, and poorer survival.

\section{Methods:}

The Nutrition and Exercise during adjuvant Treatment (NEXT) Study was a prospective, single arm intervention study in women with breast cancer receiving adjuvant chemotherapy. It was designed to assess the effectiveness of a supervised exercise and healthy eating program offered as part of supportive care in a comprehensive cancer centre, in Vancouver, BC, Canada. Women with early stage breast cancer $(n=73)$ were enrolled within the first half of their prescribed chemotherapy. Groupbased, supervised aerobic and resistance exercise training was performed three times per week during adjuvant treatment (chemotherapy \pm radiation) and 1-2 times per week for 20 weeks post-treatment. Participants also attended a single group-based healthy eating information session with a registered dietitian. Body weight and waist circumference were measured and Body Mass Index was calculated at baseline $(n=73)$ and three additional time points including end of adjuvant treatment (T1) $(n=57)$, end of program (T2) ( $n=59)$, and one year follow-up (T3) $(n=46)$. Each outcome was analyzed using a generalized linear mixed model and Bonferroni adjustment for multiple comparisons was used to detect significant differences $(p<0.01)$ between time points.

\section{Results:}

There was no increase in body weight, waist circumference or Body Mass Index observed from baseline to any successive time points $(p>0.05)$. The trend for body weight from baseline was $-1.1 \mathrm{~kg}(\mathrm{~T} 1),-2.2 \mathrm{~kg}$ (T2) and $-2.7 \mathrm{~kg}$ (T3), which reached statistical significant at one year follow-up. The trend for waist circumference from baseline was $-2 \mathrm{~cm}$ (T1), $-4 \mathrm{~cm}$ (T2) and $5 \mathrm{~cm}$ (T3), which reached statistical significance at end of program and at one year follow-up $(p<0.01)$.

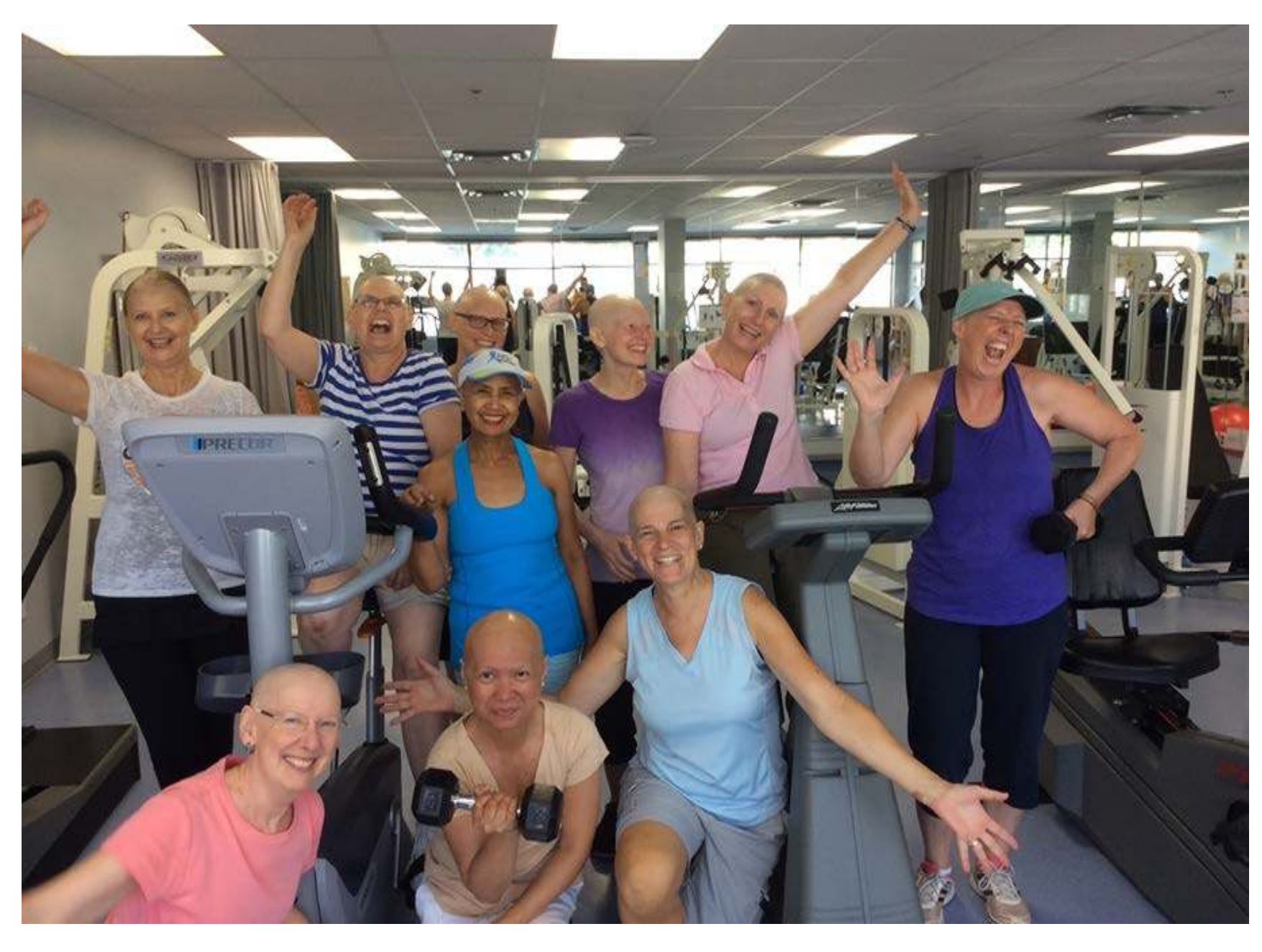

Table 1: Participant Body Weight and Waist Circumference Changes Over Time

\begin{tabular}{|c|c|c|}
\hline & $\begin{array}{c}\text { Body } \\
\text { Weight }(\mathbf{k g})\end{array}$ & $\begin{array}{c}\text { Waist } \\
\text { Circumference }(\mathrm{cm})\end{array}$ \\
\hline $\begin{array}{c}\text { Baseline } \\
(\mathbf{n}=73)\end{array}$ & $69.9 \pm 17.7$ & $89 \pm 14$ \\
\hline $\begin{array}{c}\text { End of Treatment } \\
(\mathbf{n}=57)\end{array}$ & $68.8 \pm 15.7$ & $87 \pm 13$ \\
\hline $\begin{array}{c}\text { End of Program } \\
(\mathbf{n}=59)\end{array}$ & $67.7 \pm 17$ & $85 \pm 13^{*}$ \\
\hline $\begin{array}{c}\text { One-year } \\
\text { Follow-up } \\
(\mathbf{n}=46)\end{array}$ & $67.2 \pm 14.3^{\star}$ & $84 \pm 12^{*}$ \\
\hline${ }^{*} p<0.01$ from baseline & \\
\hline
\end{tabular}

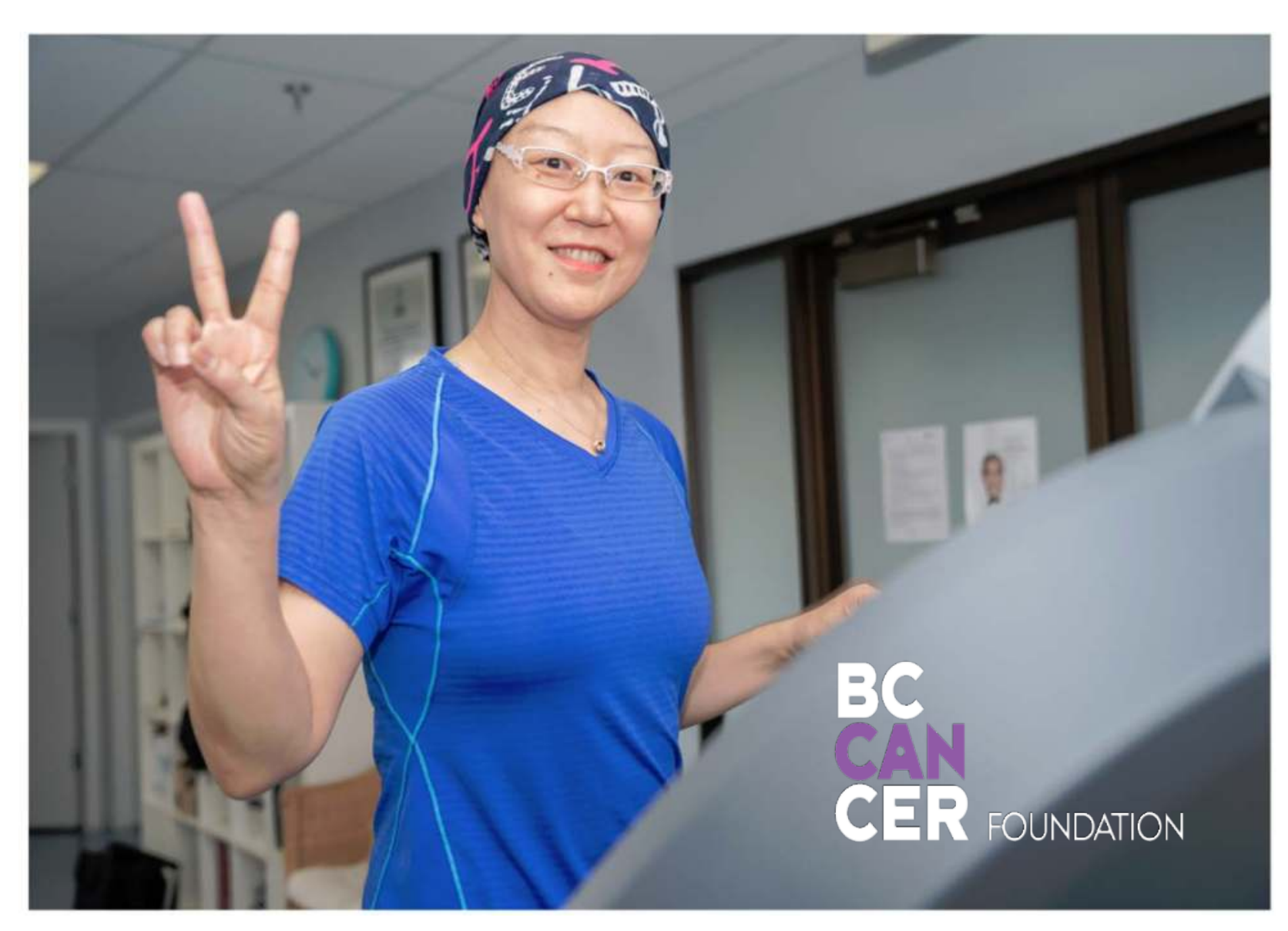

\section{Conclusion:}

Women engaging in supervised exercise training and nutritional counselling as part of supportive care were able to maintain their weight during adjuvant breast cancer therapy. With continued exercise training following completion of cancer treatment women demonstrated significant reductions in body weight and waist circumference.

\section{Publication of primary endpoints:}

Kirkham, AA, Van Patten, CL, Gelmon, KA, McKenzie, DC, Bonsignore, A, Bland, KA, Campbell, KL. Effectiveness of Oncologist-Referred Exercise and Healthy Eating Programming as a Part of Supportive Adjuvant Care for Early Breast Cancer. The Oncologist 2018; 23: 105-115. 